\section{Structural Changes during the Fatigue of Copper}

RECENT experiments on annealed low-oxygen highconductivity copper have shown that, under direct fatigue stresses, the structural changes revealed by back-reflexion X-ray photographs (cobalt $K \alpha$ radiation ; film-to-specimen distance, $10 \mathrm{~cm}$.) are markedly dependent upon mean cyclical load.

The tests were carried out on a variable-frequency testing machine, which applied alternate tensile and compressive loads to the test specimen. The mean cyclical loads were conveniently varied within restricted limits by placing weights on a counterbalance pan which was attached to the straining device of the machine by a flexible steel cable passing over a pullev.

At frequencies of both $200 \mathrm{c} / \mathrm{min}$. and $400 \mathrm{c} . / \mathrm{min}$., small variations in the value of the counterweight attached to the straining device were found to produce disproportionate changes in the $\mathrm{X}$-ray diffraction patterns of test-specimens after 1,000 stress cycles at about \pm 5 tons $/ \mathrm{sq}$. in. At the same time, permanent dimensional changes were similarly influenced by variations in the magnitude of the counterweight, as will be soen from Table 1 .

Table 1. Permanent Strains after 1,000 CyCles at \pm 5 TONS/SQ. IN APPROXIMATELY

\begin{tabular}{|c|c|c|c|}
\hline \multicolumn{2}{|c|}{$200 \mathrm{c} . / \mathrm{min}$. tests } & \multicolumn{2}{|c|}{$400 \mathrm{c} / \mathrm{mnin}$. tests } \\
\hline $\begin{array}{c}\text { Counterweight } \\
\text { (lb.) }\end{array}$ & $\begin{array}{c}\text { Permanent } \\
\text { strain (per cent) }\end{array}$ & $\begin{array}{c}\text { Counterweight } \\
\text { (lb.) }\end{array}$ & $\begin{array}{c}\text { Permanent } \\
\text { strain (per cent) }\end{array}$ \\
\hline 40 & -1 & 40 & -1 \\
60 & -0.3 & 80 & $\begin{array}{c}\text { Nil } \\
+1.5\end{array}$ \\
\hline 80 & +1 & 120 & +1 \\
\hline
\end{tabular}

In those cases where the permanent dimensional changes were slight or negligible, the X-ray patterns showed relatively small changes except for a general diffusion of the sharp diffraction spots typical of the annealed material (see Fig. 1). However, the changes in the patterns were quite pronounced in all cases where the permanent dimensional changes exceeded about \pm 1 per cent, at both high and low frequencies (see Fig. 2).

Wood and Hoad ${ }^{2}$, in their direct reversed-stress tests on oxygen-free high-conductivity copper, attributed their observations of pronounced diffusion and circumferential arcing of X-ray diffraction spots at 'sub-critical' testing frequencies $(<350 \mathrm{c} / \mathrm{min}$. approximately) and the relative absence of changes at higher frequencies to the influence of a delay period, representing the finite time between application of a stress and development of the corresponding plastic strain. These tests were done on the machine used in the present work.

However, repeated tension experiments which I have carried out on similar material have shown that the use of the higher testing frequencies fails to inhibit structural changes (as revealed by $\mathrm{X}$-ray diffraction) and dimensional changes, at least after 100 cycles.

Other work ${ }^{3}$ has shown that, even under static loading conditions, annealed copper can withstand reversed stresses of \pm 5 tons/sq. in. with only slight changes in X-ray diffraction patterns, providing a suitable 'stepped' loading sequence is followed. It is clear that, in this latter case, structural changes are minimized by the choice of an appropriate preliminary

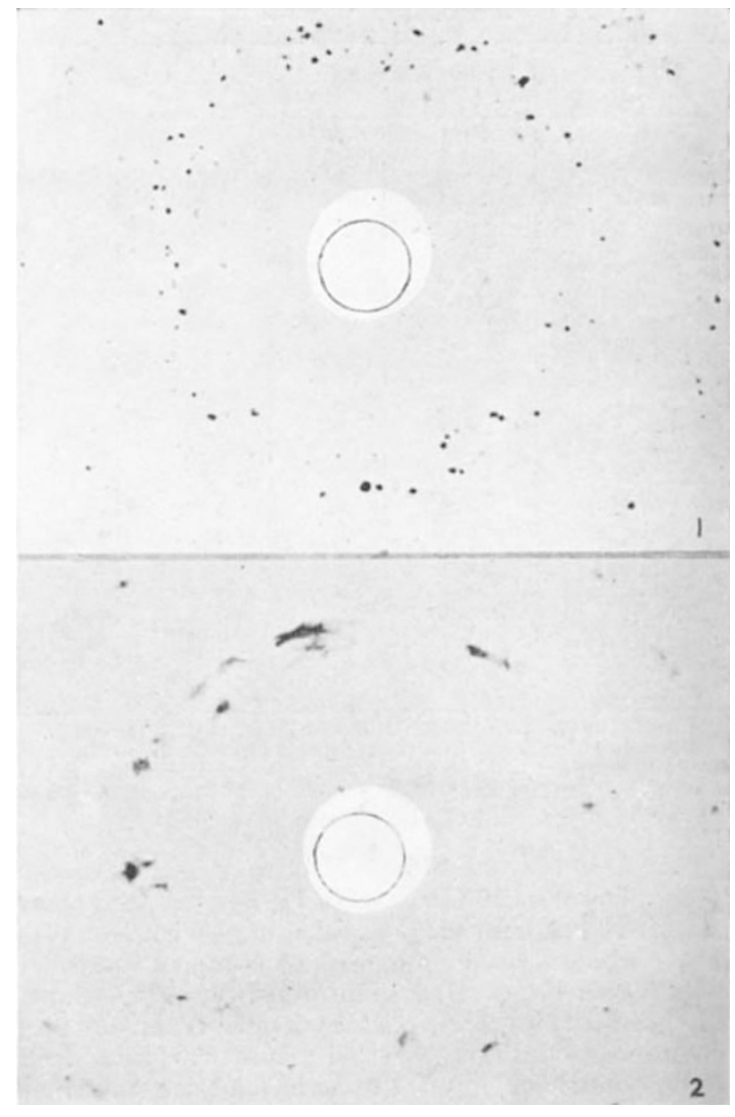

Diffraction patterns: (1) specimen which showed zero extension after 1,000 stress cycles at $400 \mathrm{c} / \mathrm{min}$.; (2) specimen which suffered 1.5 per cent elongation after 1,000 stress eycles at $400 \mathrm{c} . / \mathrm{min}$.

loading schedule rather than by any time-delay mechanism.

The marked dependence of structural and dimensional changes upon mean cyclical load in direct-stress tests can result in an erroneous impression being obtained of the nature and extent of fundamental structural changes under fatigue stresses, unless loadbalancing operations of high precision are practised. In the absence of confirmatory evidence from lowand high-frequency tests carried out in other types of machines (for example, rotating bending tests), it scems possible that the critical-frequency effect reported by Wood and Head ${ }^{2}$ may have been attribut. able primarily to progressive dimensional changes arising from characteristics of the testing machine.

Some preliminary rotating bending tests have, in fact, been carried out, and X-ray diffraction studies have indicated that the structural changes, even at 21 c./min., may be relatively slight.

Acknowledgment is mado to the Chief Scientist, Department of Supply, for permission to publish this communication.

Aeronautical Research Laboratories,

\section{R. B. Davies}

Department of Supply,

Melbourne.

July 2.

1 Johnstone, W. W., and Peggie, J. B., Comm. Aust., Dept. Supply. Aero. Res. Lab., S. and M. Note 190 (1951).

2 Wood, W. A., and Head, A. K., J. Inst. Metals, 73 (2), 89 (1951).

s Wood, W. A., and Davies, R. B., Proc. Roy. Soc., A. 220. 255 (1953). 